\title{
Pten Deletion in Adult Hippocampal Neural Stem/Progenitor Cells Causes Cellular Abnormalities and Alters Neurogenesis
}

\author{
Anahita Amiri, ${ }^{1}$ Woosung Cho, ${ }^{1}$ Jing Zhou, ${ }^{1}$ Shari G. Birnbaum, ${ }^{2}$ Christopher M. Sinton, ${ }^{3}$ Renée M. McKay, \\ and Luis F. Parada ${ }^{1}$ \\ Departments of ${ }^{1}$ Developmental Biology, ${ }^{2}$ Psychiatry, and ${ }^{3}$ Internal Medicine, University of Texas Southwestern Medical Center, Dallas, Texas $75390-9133$
}

Adult neurogenesis persists throughout life in restricted brain regions in mammals and is affected by various physiological and pathological conditions. The tumor suppressor gene Pten is involved in adult neurogenesis and is mutated in a subset of autism patients with macrocephaly; however, the link between the role of PTEN in adult neurogenesis and the etiology of autism has not been studied before. Moreover, the role of hippocampus, one of the brain regions where adult neurogenesis occurs, in development of autism is not clear. Here, we show that ablating Pten in adult neural stem cells in the subgranular zone of hippocampal dentate gyrus results in higher proliferation rate and accelerated differentiation of the stem/progenitor cells, leading to depletion of the neural stem cell pool and increased differentiation toward the astrocytic lineage at later stages. Pten-deleted stem/progenitor cells develop into hypertrophied neurons with abnormal polarity. Additionally, Pten mutant mice have macrocephaly and exhibit impairment in social interactions and seizure activity. Our data reveal a novel function for PTEN in adult hippocampal neurogenesis and indicate a role in the pathogenesis of abnormal social behaviors.

\section{Introduction}

Phosphatase and tensin homolog on chromosome 10 (PTEN) is a tumor suppressor gene that is frequently mutated in human cancers and plays an important role in brain development ( $\mathrm{Li}$ et al., 1997; Endersby and Baker, 2008). Neurological features of inherited PTEN mutations include macrocephaly, seizures, and mental retardation (Waite and Eng, 2003; Endersby and Baker, 2008). PTEN is a negative regulator of phosphatidylinositol-3kinase (PI3K) signaling (Maehama and Dixon, 1998). Changes in the activity of $\mathrm{PI} 3 \mathrm{~K} / \mathrm{AKT} / \mathrm{mTOR} / \mathrm{GSK} 3 \beta$ pathway components have been associated with diverse brain disorders such as brain tumors, schizophrenia, and autism.

Autism spectrum disorders (ASDs) are a group of complex neurodevelopmental conditions (Silverman et al., 2010). Pten mutations have been identified in autistic patients with macrocephaly (Goffin et al., 2001; Butler et al., 2005; Buxbaum et al., 2007; Varga et al., 2009). Conditional Pten KO mouse models have been used to investigate the role of Pten in the nervous system (Backman et al., 2001; Groszer et al., 2001; Kwon et al., 2001; Marino et al., 2002; Fraser et al., 2004; Yue et al., 2005). Deletion of Pten in mature neuronal populations in the cerebral cortex and hippocampus resulted in macrocephaly, abnormal dendritic and axonal growth and synapse number. These mice

Received 0ct. 28, 2011; revised Feb. 28, 2012; accepted March 3, 2012.

Author contributions: A.A., W.C., J.Z., S.G.B., C.M.S., and L.F.P. designed research; A.A., W.C., S.G.B., and C.M.S. performed research; A.A., W.C., J.Z., S.G.B., C.M.S., R.M.M., and L.F.P. analyzed data; A.A. wrote the paper.

This work was supported by a grant to L.F.P. from The Simons Foundation (SFARI). We thank Ami Pettersen and Efrain Sanchez-Ortiz for technical assistance.

Correspondence should be addressed to Luis F. Parada, Department of Developmental Biology, University of Texas Southwestern Medical Center, Dallas, TX 75390-9133. E-mail: luis.parada@utsouthwestern.edu.

DOI:10.1523/JNEUROSCI.5462-11.2012

Copyright $\odot 2012$ the authors $\quad 0270-6474 / 12 / 325880-11 \$ 15.00 / 0$ also showed behavioral abnormalities resembling certain features of human ASDs (Kwon et al., 2006; Ogawa et al., 2007). Mouse models based on Pten deletion in the brain have also provided information about the role of Pten in neural stem/progenitor cell (NSC) proliferation and self-renewal (Groszer et al., 2001; Gregorian et al., 2009). Mice with Pten deletion in embryonic NSCs had enlarged brains due to increased NSC proliferation, decreased cell death, and enlarged cell size (Groszer et al., 2001). Pten was also shown to play a role in adult NSC regulation in the SVZ of the lateral ventricles (Gregorian et al., 2009). Conditional deletion of Pten in a subpopulation of adult NSCs in the SVZ resulted in enhanced self-renewal in these cells. The Pten-deleted mice had enlarged olfactory bulb (OB) and enhanced olfactory function. In adult hippocampus, the majority of the NSC progeny engender dentate granule cells. Adult hippocampal neurogenesis has been implicated in antidepressive responses, spatial relational memory and spatial pattern recognition (Li et al., 2008; Clelland et al., 2009; Jessberger et al., 2009).

Here, we use the tamoxifen-inducible Nestin-CreER ${ }^{T 2}$ line ( $\mathrm{Li}$ et al., 2008; Chen et al., 2009) to delete Pten specifically in postnatal/young adult NSCs. We find that Pten conditional mutant mice develop macrocephaly with an enlarged DG and a disorganized granule cell layer. Additionally, these mice have altered neurogenesis; Pten-deleted adult NSCs display an increased proliferation and differentiation rate and develop into hypertrophied neurons. Over months, this increased differentiation rate leads to early depletion of NSCs. Finally, we show that the Pten mutant mice exhibit significant impairment in social interaction tests and infrequent generalized seizures. These data reveal a novel function for PTEN in adult hippocampal neurogenesis, and are consistent with a possible role for PTEN and hippocampal stem cells in the pathogenesis of autism-like behaviors. 
A
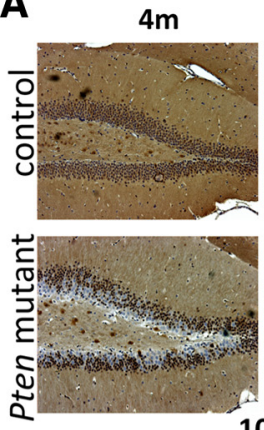

$10 X$

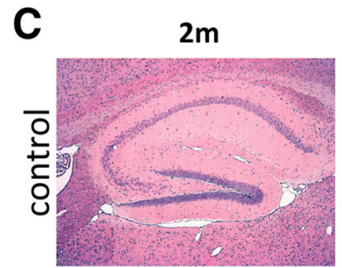

c

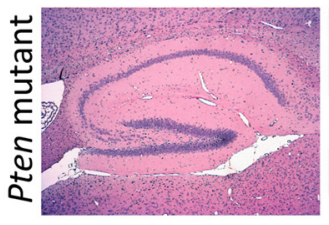

$7 m$
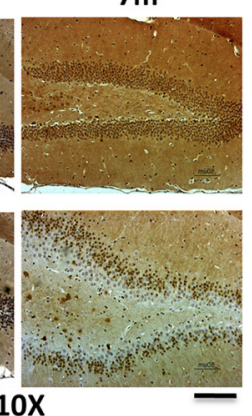

$4 m$
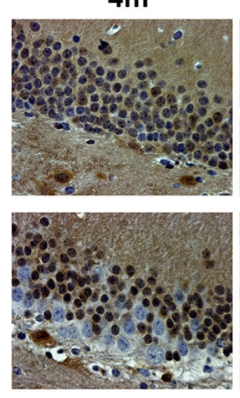

$7 m$
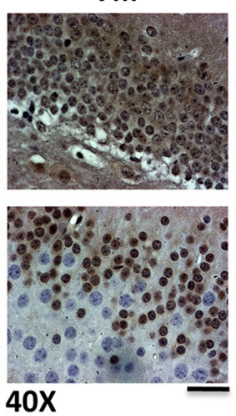

B
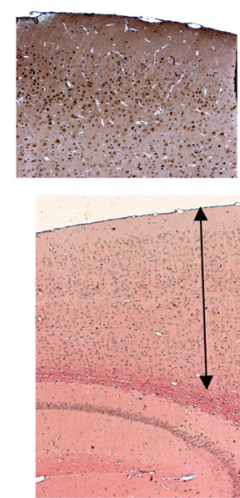

Pten mutant
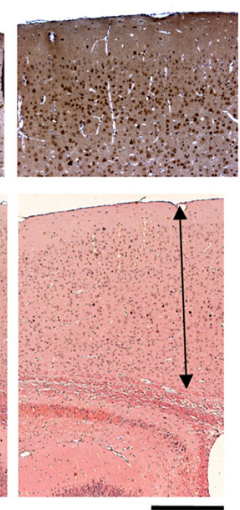

$4 m$
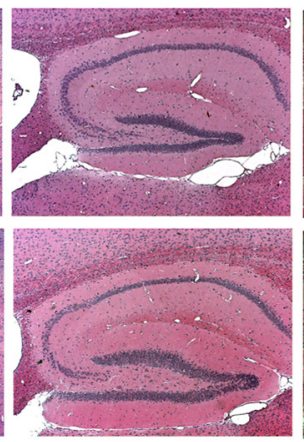

$7 m$
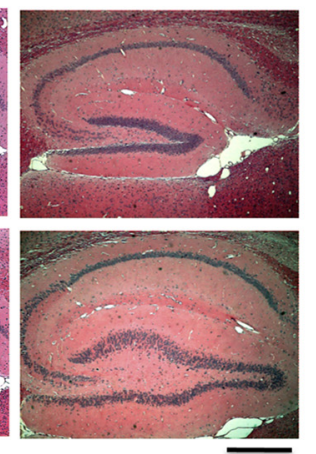

Figure 1. Pten ablation in the SGZ. PTEN immunostaining of hippocampus from control and mutant mice. A, At 4 and 7 months of age, Pten-negative (blue) cells were detected in the SGZ. Pten-positive (brown) cells were detected in the polymorphic layer and the outer granular layer. At 7 months of age, Pten-negative cells were larger and the dentate gyrus was disorganized. Scale bars: Left, $200 \mu \mathrm{m}$; right, $50 \mu \mathrm{m}$. B, PTEN (brown) was detectable in the cortex of both control and mutant mice, and cortex size was the same. Scale bar, $500 \mu \mathrm{m}$. C, H\&E staining of hippocampus from 2-, 4-, and 7-month-old Pten mutant mice shows progressive enlargement and disorganization of dentate gyrus. Scale bar, $500 \mu \mathrm{m}$.

\section{Materials and Methods}

Mice and histology. Pten ${ }^{l o x P}$ mice (Suzuki et al., 2001) were a gift from Tak Mak (University of Toronto, Canada). Nestin-CreER ${ }^{T 2}$ mouse line was generated as previously described (Chen et al., 2009). R26 mice were from Jackson Laboratory. All animals were maintained on C57BL/6 and $129 / \mathrm{Sv}$ mixed background. Tamoxifen (Sigma) was dissolved in sunflower oil at $20 \mathrm{mg} / \mathrm{ml}$ and delivered to 1 -month-old mice by gavage at $500 \mu \mathrm{l} / 20 \mathrm{~g}$, once a day for 2 consecutive days. For BrdU pulse/chase assay, we injected $\mathrm{BrdU}(200 \mu \mathrm{g} / \mathrm{g})$ intraperitoneally $2 \mathrm{~h}$ before perfusion. For cell survival analysis, mice were injected with BrdU $(50 \mu \mathrm{g} / \mathrm{g})$ daily for $5 \mathrm{~d}$ at 6 months of age and analyzed 4 weeks after the last injection. The mice were perfused intracardially with ice-cold PBS followed by $4 \%$ PFA in PBS. Dissected brains were postfixed in 4\% PFA at $4^{\circ} \mathrm{C}$ overnight. For vibratome sectioning, we embedded the brain in $3 \%$ agarose and cut $50 \mu \mathrm{m}$ thick coronal sections. For paraffin sectioning, the brain was embedded in paraffin and sectioned sagittally at $5 \mu \mathrm{m}$ thickness. All mouse procedures used in this study were performed in accordance with protocols approved by the Institutional Animal Care and Research Advisory Committee at University of Texas Southwestern Medical Center.

Neural progenitor cell culture. Dentate gyrus neural progenitor cells (NPCs) were isolated and maintained as described previously ( $\mathrm{Li}$ et al., 2008). Monolayer cultures were established as described previously (Babu et al., 2007) with some modifications. Briefly, cells were cultured on plates coated with laminin (Invitrogen) in DMEM/F12 media (Invitrogen) containing B27 (without vitamin A, Invitrogen), epidermal growth factor (20 ng/ml, Invitrogen), and basic fibroblast growth factor (20 ng/ml, Sigma). Monolayer cultures were treated with adenovirus particles that expressed either the GFP or the Cre-GFP gene (Gene Transfer Vector Core, University of Iowa). Loss of PTEN was confirmed by Western blot analysis. Differentiation was induced following $3 \mathrm{~d}$ of growth by removing growth factors (EGF and bFGF) from the medium.
Cells were allowed to differentiate for $3 \mathrm{~d}$. Cell growth rate was measured by an ATP assay using the luminescent CellTiter-Glo assay according to the manufacturer's instructions (Promega). For these experiments, 3000 cells/well were plated in laminin-coated 96-well plates. Apoptosis was measured using the Caspase-Glo 3/7 kit (Promega) according to the manufacturer's recommendations.

Behavioral tests. All animals used for behavioral tests were male and littermates. Social interaction and memory, social preference, open field activity, light/dark preference, and tail suspension tests were performed using 4- to 5-month-old-mice. Social olfactory, startle reflex, and rotarod tests were performed using 7-month-old mice. Locomotor activity, open-field, dark-light, and tail suspension tests were measured as described previously (Li et al., 2008). Social interaction and memory, and social preference tests were measured as described previously (Kwon et al., 2006).

EEG/EMG recording. Ten Nestin-CreER ${ }^{T 2} ;$ Pten $^{\text {loxp } / l o x p}$ mice (male, 15-20 weeks old at the time of surgery) were instrumented with chronically implanted EEG/EMG electrodes according to previously published procedures (Sinton et al., 2009). The mice were then left for $14 \mathrm{~d}$ to recover from surgery and to habituate to the recording conditions. Food and water were available ad libitum at all times and the temperature was maintained at $24 \pm 1^{\circ} \mathrm{C}$ throughout the experiment. EEG/EMG signals were recorded continuously during $24 \mathrm{~h}$ periods: 2 mice were recorded for 5 periods of $24 \mathrm{~h}, 4$ mice for 10 periods of $24 \mathrm{~h}$, and 4 mice for 13 periods of $24 \mathrm{~h}$ for a total of $\sim 2500 \mathrm{~h}$ of recording. All records were then visually scored for seizure events. The spontaneous seizure rate in these mice was very low, and multiple attempts to induce seizures with exogenous auditory or visual stimuli were unsuccessful.

Immunostaining. The following antibodies were used for immunohistochemistry: PTEN, P-AKT, P-S6, P-GSK3 $\beta$ (Cell Signaling Technology), Calbindin (Swant), Synapsin I (Millipore), BrdU (BD Biosciences), Doublecortin (Santa Cruz Biotechnology), Ki67 (NeoMarker), NeuN 
A

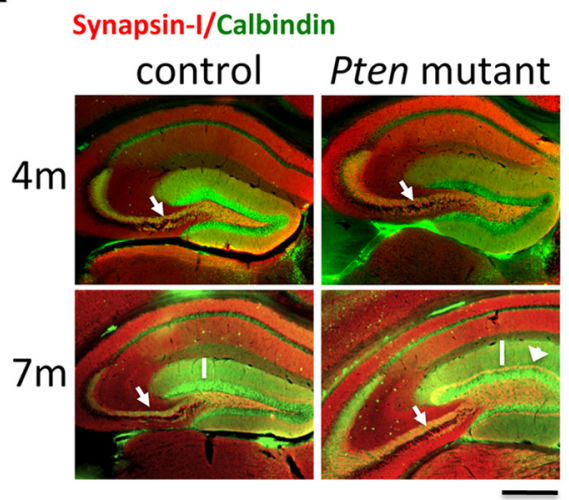

B

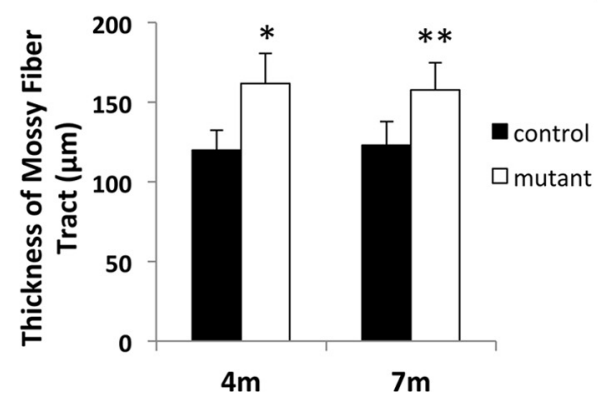

C
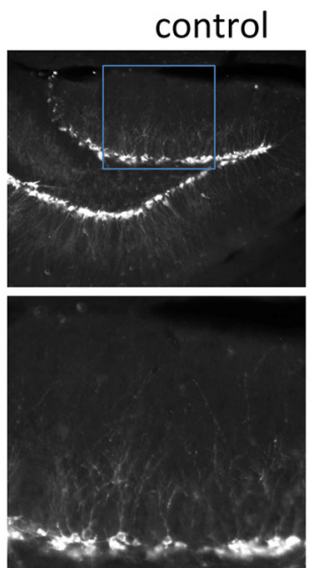

mutant

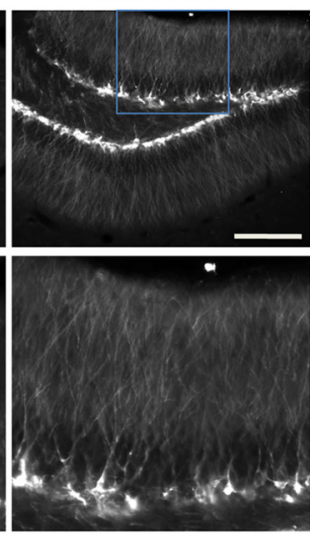

Figure 2. Dendritic and axonal hypertrophy and ectopic axonal tracts in Pten mutants. A, Floating sections ( $50 \mu \mathrm{m}$ ) of brains from 4- and 7-month-old control and mutant mice were stained for Synapsin I (red) and Calbindin (green). Elongated mossy fiber tract from the granular layer of mutant dentate gyrus is shown in both 4- and 7-month-old mutant brains (arrows). An ectopic layer of axonal signals (arrowhead) in the inner molecular layer is observed in 7-month-old mutant brain. Scale bar, $500 \mu$ m. $\boldsymbol{B}$, Quantification analysis shows that mutant mice have increased thickness of mossy fiber tract, as measured by the width of Synapsin I and Calbindin double-stained axons coming out of DG. $n=3$ for control and mutant for 4 -month-old mice; $n=6$ for control and $n=5$ for mutant for 7-month-old mice. C, DCX immunostaining of 2-month-old mutant brain shows hypertrophy and arborization of dendrites. Bottom, High-magnification images of the boxes in the top. Scale bar, $200 \mu \mathrm{m}$. Data are mean $\pm \mathrm{SEM} ; t$ test was used for all analyses. ${ }^{*} p<0.05,{ }^{* *} p<0.01$.

(BD Biosciences), $S 100 \beta$ (Sigma), GFP (Molecular Probes), Tuj1 (Covance), and Sox2 (Millipore). Microwave antigen retrieval was used for all antibodies on paraffin sections. Sections were then treated with biotinylated secondary antibodies followed by amplification with peroxidase-conjugated avidin and DAB substrate (Vector Laboratories). We counterstained DAB-stained sections with hematoxylin. Methyl green was used for counterstaining of P-GSK $3 \beta$-stained sections. Alternatively, primary antibodies were visualized with Cy2- and Cy3conjugated antibodies (Jackson ImmunoResearch).

Measurements. We used MetaMorph and ImageJ (NIH) software for all measurements. The thickness of mossy fiber tract and dendritic size were measured as described previously (Zhou et al., 2009). The number of Ki67-, doublecortin (DCX)-, and BrdU-positive cells was measured on $50 \mu \mathrm{m}$ floating sections and presented as the average number per section. Six sections per animal were examined. Student's $t$ tests were used to determine statistical differences. A $p$ value of $<0.05$ was considered statistically significant.

Western blotting. Isolated brain tissues were snap frozen in liquid nitrogen and then homogenized in Cell Lysis Buffer (Cell Signaling Technology) containing Phosphatase and Protease Inhibitor Cocktail (Calbiochem). Western blotting was performed as described by Zhou et al. (2009). Antibodies used for Western blotting were P-AKTSer473, P-GSK3B, P-S6 (Ser235/236), AKT, GSK3b, and S6 (Cell Signaling Technology).

\section{Results}

\section{Pten inactivation in adult hippocampal NSCs}

We have previously shown that deletion of Pten in a subset of mature neurons in hippocampus and cortex causes abnormal neuronal hypertrophy and ASD-like social deficits in mice. To evaluate the role of Pten in a more restricted subset of cells and brain regions, we used the Nestin-cre;Pten ${ }^{\text {loxp/loxp }}$ mice to delete
Pten in adult hippocampal NSCs. Nestin-CreER ${ }^{T 2}$ mice activate Cre recombination by tamoxifen administration (Chen et al., 2009).Thus, administering tamoxifen at 4 weeks of age to NestinCreER ${ }^{T 2}$ mice harboring the Rosa26-lacZ reporter locus (Soriano, 1999) allowed us to label and trace the young adult NSCs and their recombinant progeny in the two major adult neurogenic niches, the subgranular zone (SGZ) of the dentate gyrus and the SVZ of the lateral ventricle (data not shown).

To ablate Pten in the SGZ, we crossed the Nestin-creER ${ }^{T 2}$ mouse line with Pten-flox mice and activated the Cre recombinase by tamoxifen administration at 4 weeks of age. Littermate Pten ${ }^{\text {loxp/loxp }}$ mice treated with tamoxifen were used as controls. PTEN immunostaining of dentate gyrus from 4- and 7-monthold mice showed that Pten was successfully deleted in the SGZ (Fig. 1A). Cells born before the tamoxifen induction retained PTEN expression. PTEN loss was confined to adult germinal zones and was retained elsewhere, for example in the cortex where Cre was not activated (Fig. $1 B$ ).

\section{Progressive hypertrophy in Nestin-creER ${ }^{T 2}$ Pten $^{\text {loxp/loxp }}$ mutant brain}

Dentate gyrus granule neurons are born in the SGZ and migrate a short distance into the dense granule layer. Three months after tamoxifen induction ( 4 months of age), there was obvious disorganization of the mutant GCL, which was accompanied by hypertrophy of newly generated neurons in the inner granular layer (Fig. $1 A, C$ ). At 7 months of age, the disorganized GCL phenotype was more pronounced. This hippocampal phenotype is similar to that previously observed in Nse-cre;Pten ${ }^{\text {loxp/loxp }}$ mutant mice, al- 
A

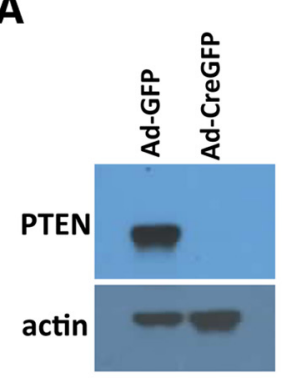

C
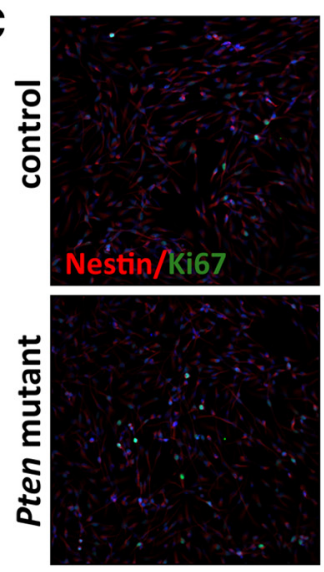
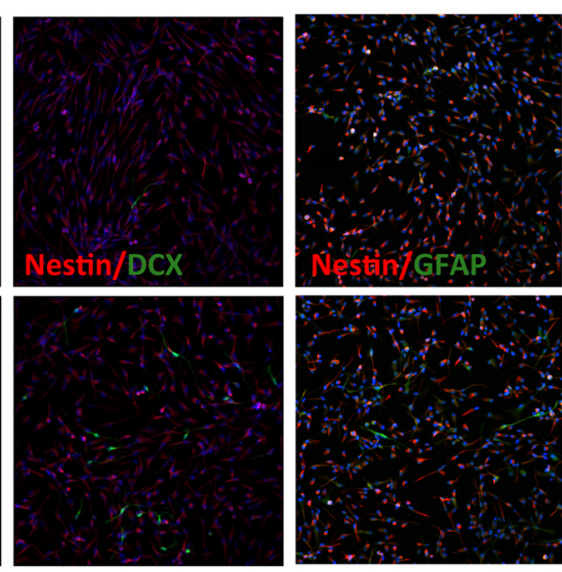

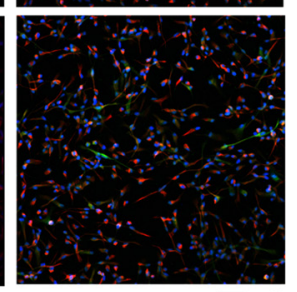

\section{B}

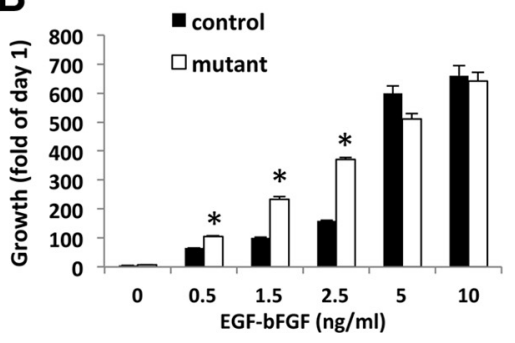

Figure 3. Pten ablation enhances proliferation of hippocampal NSCs in vitro. NSCs isolated from dentate gyrus of Pten ${ }^{\text {loxp/loxp }}$ mice were grown in monolayer culture and infected with adenovirus (Ad) containing GFP (control) or CreGFP (to delete Pten). $A$, No PTEN protein was detected in Ad-CreGFP NSCs by Western blotting. $\boldsymbol{B}$, Pten-deleted NSCs showed decreased growth factor dependency, but still required EGF and bFGF for growth, as they did not grow in media without these growth factors. At 0.5 and $2.5 \mathrm{ng} / \mathrm{ml}$ concentration of EGF-bFGF, Pten KO had a 1.6- and 2.3-fold increase in cell growth compared with control, respectively. However, at higher concentrations $(5-10 \mathrm{ng} / \mathrm{ml})$, no differences were observed in growth rate between Pten-deleted and control cultures. Data are mean \pm SEM; $t$ test was used for all analyses. $n=8 ;{ }^{*} p<0.0001$. C, Control and Pten KO cultures were grown in the presence of growth factors (EGF and bFGF) and double-stained with antibodies against Nestin and Ki67, Nestin and DCX, and Nestin and GFAP. Scale bar, $50 \mu \mathrm{m}$.

though in those mice Pten was deleted only in postmitotic granule neurons (Kwon et al., 2006). These data suggest that following Pten deletion, adult SGZ stem/progenitor cells are able to at least partially differentiate and integrate into the deeper granule layers. Unlike in the Nse-cre; Pten ${ }^{\text {loxp } / l o x p}$ mice, Pten was not deleted in the cortex in this mouse model and we did not observe any detectable changes in the cortex (Fig. $1 B$ ).

Broad and restricted CNS deletion of Pten has been shown to cause macrocephaly (Groszer et al., 2001; Kwon et al., 2001, 2006). Similarly, we observed macrocephaly in Nestin-creER ${ }^{T 2}$; Pten $^{\text {loxp/loxp }}$ mice, with brain weight in mutant mice $\sim 4 \%$ heavier than in control mice at 7 months of age $(538 \pm 6.11 \mathrm{mg}$ in control vs $562.7 \pm 7 \mathrm{mg}$ in mutant, mean \pm SEM; $n=8$ for each; Student's $t$ test; $p<0.05)$. Body weight did not differ between the two groups (data not shown).

\section{Adult NSCs lacking Pten form neurons with abnormal axons and dendrites}

In the dentate gyrus, newly formed granule cells extend their dendrites to the molecular layer and their axons project from the granule layer through the polymorphic layer to synapse with CA3 dendrites forming the mossy fiber tract (Amaral, 1978). PTEN is known for its involvement in neurite outgrowth both in vitro and in vivo (Markus et al., 2002; Kwon et al., 2006). We examined DG axonal and dendritic projections of developing granule neurons in mice deleted for Pten at 1 month of age and immunostained at 3 and 6 months after tamoxifen induction. IHC analysis was performed with Synapsin I, a presynaptic marker, and Calbindin, to mark both soma and granule neuron processes. We observed an $\sim 1$.3-fold increase in mossy fiber tract thickness at both 4 and 7 months of age (Fig. $2 A, B$ ). In addition, the Pten mutants had elongated dendrites, as measured by the thickness of the molecular layer (ML) (Fig. 2A, bottom, white lines) $(208 \pm 2.46 \mu \mathrm{m}$ in controls vs $273 \pm 12.1 \mu \mathrm{m}$ in mutants; mean \pm SEM; $n=4$; Student's $t$ test; $p<0.01$ ), with more arborization (Fig. $2 C$ ). These data indicate that the Pten mutant neural progenitors developed into hypertrophic neurons with enlarged axons and dendrites, similar to the results obtained previously by ablating Pten exclusively in differentiated DG neurons (Kwon et al., 2006). In addition, similar to our previous observation in Nse-cre;Pten ${ }^{\text {loxp/loxp }} \mathrm{mu}$ tant mice, ectopic synapsin I staining was seen in the inner molecular layer of 7-month-old mutant mice (Fig. $2 \mathrm{~A}$, arrowhead), suggesting that following Pten deletion in SGZ NSCs, developing granule neurons have abnormal polarity.

\section{Effect of Pten deletion on adult neural stem cells in vitro}

In vitro and in vivo deletion of Pten in embryonic stem cells has been shown to enhance proliferation, survival, and self-renewal (Groszer et al., 2001, 2006). Furthermore, conditional deletion of Pten in a subpopulation of adult NSCs in the subependymal zone (SEZ) leads to increased self-renewal and neurogenesis (Gregorian et al., 2009). To assess the role of Pten in controlling adult hippocampal NSC neurogenesis, we examined Pten-deleted NSCs for their ability to promote neurogenesis in vitro. Monolayer NSC cultures were generated from isolated dentate gyrus of Pten ${ }^{\text {loxp/loxp }}$ mice. We then applied adenoviruses (Ad) containing GFP (as a control) or CreGFP (to delete Pten) to the culture. No PTEN protein was detected in Ad-CreGFP NSCs culture by Western blotting (Fig. 3A). Elevated levels of P-AKT, P-S6, and P-GSK were detected in Pten-deleted NSCs, suggesting that 
downstream signaling pathways have been affected (data not shown).

Using a luminescent ATP assay we measured cell growth in Pten KO and control NSC cultures. The PI3K pathway is activated by growth factors and is involved in neural stem/progenitor cell regulation (Caldwell et al., 2001). Figure 3B shows that deletion of Pten resulted in an increase in cell numbers in a growth factor-dependent manner. Pten-deleted NSCs still required EGF and bFGF for their growth; however, they had decreased growth factor dependency. At 0.5 and 2.5 $\mathrm{ng} / \mathrm{ml}$ concentration of EGF-bFGF, Pten KO NSCs had a 1.6- and 2.3-fold increase in cell growth compared with control, respectively. No differences were observed between Pten-deleted and control cultures at high concentrations of EGF-bFGF (5-10 ng/ml).

To test whether the observed increase in the number of Pten-deleted cells was a result of higher proliferation rate or higher survival rate, we performed a Caspase 3/7 apoptosis assay. We did not detect any differences in apoptosis activity between Pten ${ }^{\text {loxp/loxp }}$ and Pten ${ }^{-/-}$cells at $0.5-2.5 \mathrm{ng} / \mathrm{ml}$ concentrations of EGF and bFGF (data not shown). These results suggest that Pten-deleted NSCs have a higher proliferation rate.

Immunostaining showed that under normal conditions and in the presence of growth factors EGF and bFGF, most of the cells in control and Pten KO cultures were Nestin positive, suggesting that they were stem/progenitor cells (Fig. 3C). However, consistent with the ATP assay results, we observed more Ki67-positive cells in Ptendeleted NSC culture compared with control $(8 \pm 2.0$ in controls vs $24.3 \pm 2.72$ in mutants; percentage $\mathrm{Ki}^{+} 7^{+}$cells among Topro3 $^{+}$cells \pm SEM; $n=3$; Student's $t$ test; $p<0.01$ ). Ki67 is an endogenous marker of proliferation. Interestingly, under normal conditions, $7.3 \pm 0.33 \%$ (SEM) of $\mathrm{Pten}^{-1-}$ cells were positive for DCX, a marker of immature neurons, compared with $0.3 \pm 1.45 \%$ (SEM) of Pten ${ }^{\text {loxp/loxp }}$ control cells, indicating that some of the mutant cells were able to differentiate into immature neurons even in the presence of EGF and bFGF $(n=3$; Student's $t$ test; $p<0.01)$. We also observed an increase in astrocyte differentiation, as evidenced by the increase in Nestin ${ }^{-} / \mathrm{GFAP}^{+}$cells in Pten-deleted cells compared with control $(0.9 \pm 0.3$ in controls vs $5.8 \pm 0.3$ in mutants; percentage positive cells \pm SEM; $n=3$; Student's $t$ test; $p<0.05$ ).

To further explore the role of Pten in hippocampal NSC differentiation, we allowed cells to differentiate by removing EGF and $\mathrm{bFGF}$ for $3 \mathrm{~d}$ and then stained with antibodies against the cell bar, $50 \mu \mathrm{m}$.
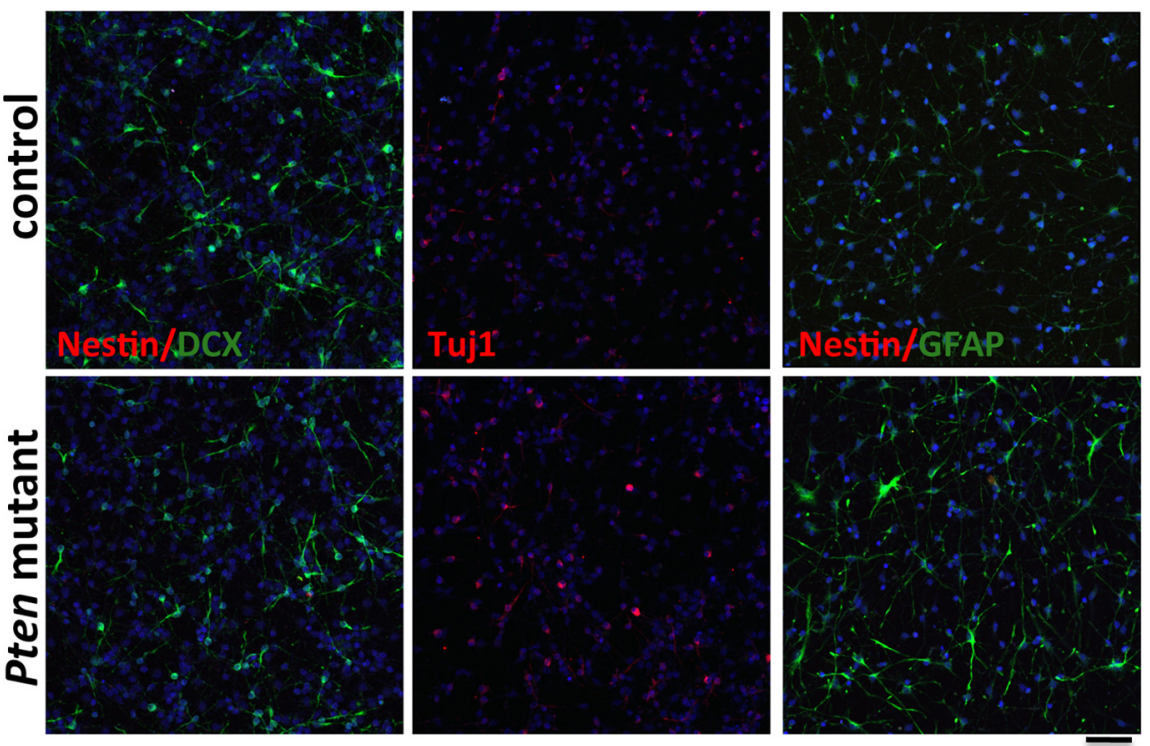

Figure 4. Pten ablation accelerates NSC differentiation in vitro. Deletion of Pten leads to a faster differentiation rate in cultured NSCs. NSCs harvested from dentate gyrus were infected with adenovirus (Ad)-GFP (control) or AD-CreGFP (mutant), induced to differentiate by removal of EGF and bFGF for $3 d$, and stained with antibodies against cell lineage-specific markers. While the number of $\mathrm{DCX}^{+}$cells (a marker of immature neurons) was the same between control and mutant, we observed $37.8 \%$ more Tuj $^{+}$(a neuronal marker) cells and 42\% more GFAP ${ }^{+}$cells in Pten ${ }^{-1-}$ mutant cells compared with Pten ${ }^{\text {loxp/loxp }}$ control. Scale

A

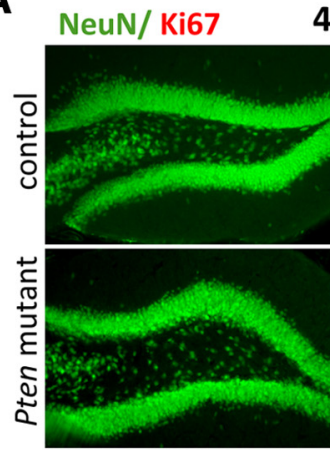

$4 m$

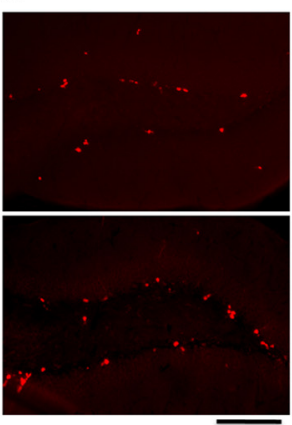

$7 m$

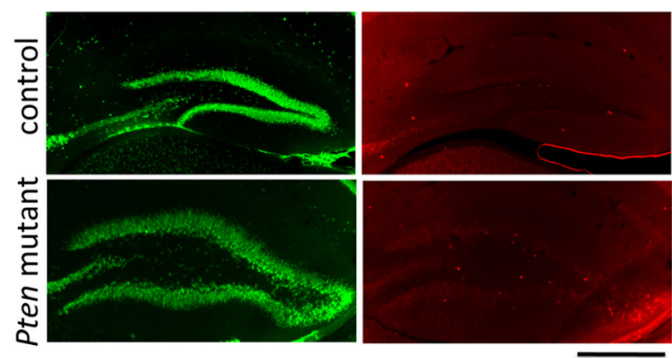

B

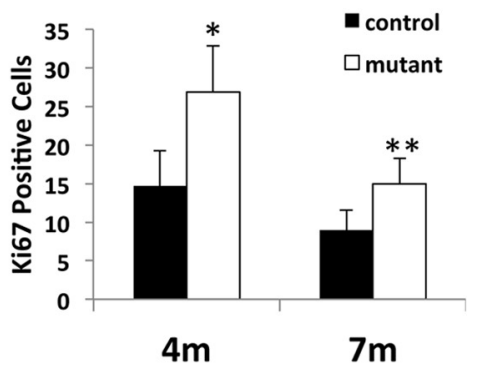

Figure 5. Pten ablation in NSCs enhances proliferation in vivo. $A$, Coronal floating sections of brains from 4- and 7-month-old mice were stained for Ki67 (red) and NeuN (green). Scale bars: Top, $200 \mu \mathrm{m}$; bottom, $500 \mu \mathrm{m}$. B, Quantification analysis showed an increase of Ki67 ${ }^{+}$cells in mutant animals. $n=4$ for control and $n=5$ for mutant for 4 -month-old mice; $n=6$ for control and mutant for 7 -month-old mice. ${ }^{*} p<0.05,{ }^{* *} p<0.01$. Data are mean \pm SEM; Student's $t$ test was used for all analyses. lineage-specific markers Tuj1 (a neuronal marker) and GFAP (Fig. 4). While the number of DCX ${ }^{+}$cells was unchanged $(19 \pm$ 1.2 in controls vs $16 \pm 2.1$ in mutants; percentage $\mathrm{DCX}^{+}$cells among Topro ${ }^{+}$cells \pm SEM; $n=3$; Student's $t$ test; $p=0.29$ ), we observed $37.8 \%$ more Tuj ${ }^{+}$cells $(16.1 \pm 1.4$ in controls vs $22.2 \pm 1.8$ in mutants; percentage of Tuj $1^{+}$cells among Topro3 ${ }^{+}$ 

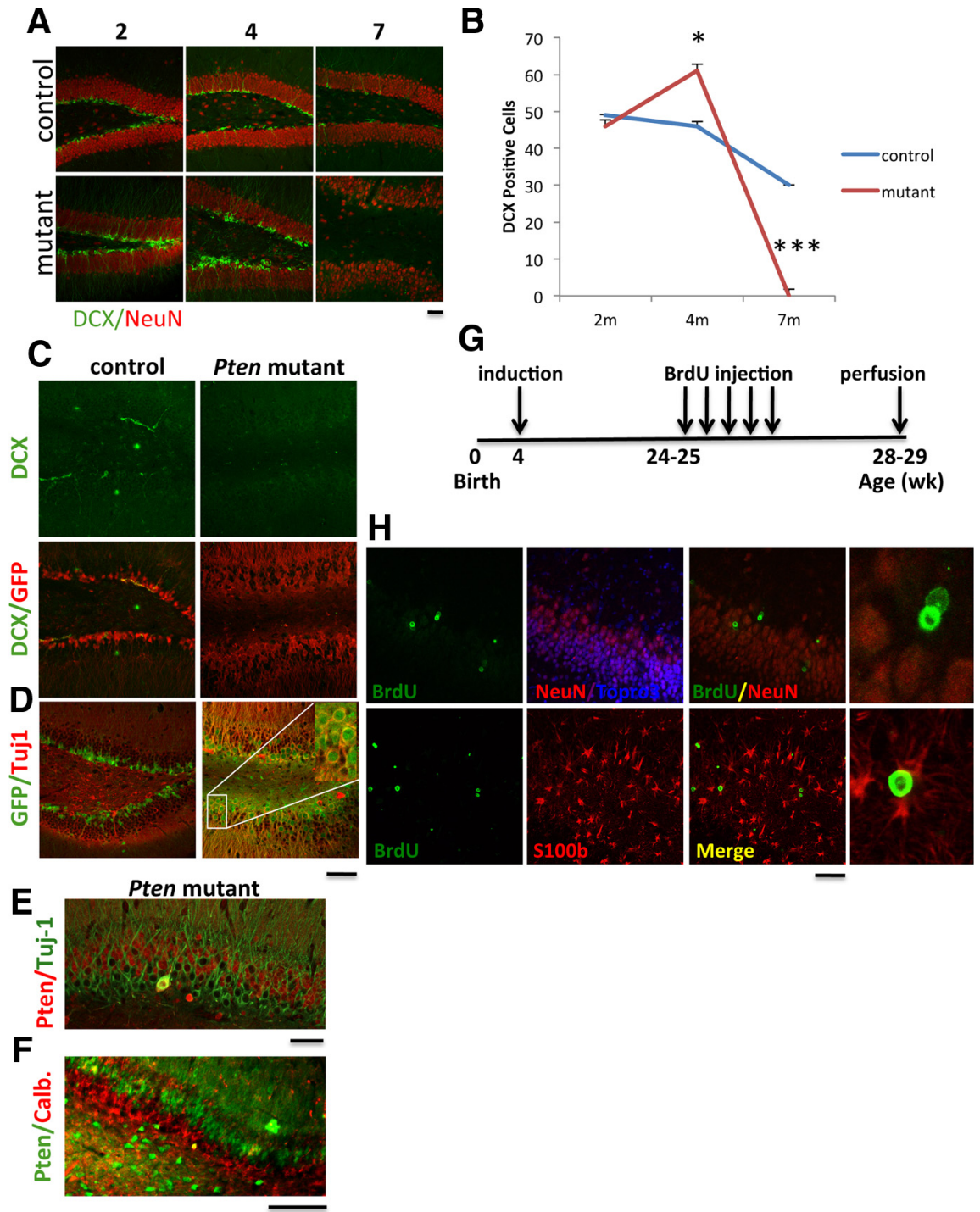

Figure 6. Loss of PTEN alters the differentiation of NSC/NPCs in vivo. A, Coronal floating sections of brain from 2-, 4-, and 7-month-old mice were stained for DCX (green) and NeuN (red). Confocal images show DCX-positive cells with elongated dendrites and more branches in 2-month-old Pten-deleted DG. By 4 months of age, there are more DCX-positive cells in Pten mutant than in control. Representative sections of brains from 7-month-old Pten mutant and control mice show lack of DCX-positive cells in mutant DG. $B$, Number of DCX-positive cells in DG of control and mutant mice at 2,4 , and 7 months of age. ( $n=3$ for 2-month-old control and mutant mice. $n=4$ for 4-month-old control and $n=5$ for mutant mice. $n=>10$ for WT and cK07-month-old mice. Data are mean \pm SEM; Student'st test was used for all analyses. ${ }^{*} p<0.05,{ }^{* * *} p<0.001$.). C, Brain sections from 7-month-old Nestin-creER ${ }^{\text {T2}}$; Pten ${ }^{\text {loxp/loxp }}$; Rosa-stop-YFP were stained for DCX (green) and YFP (using GFP antibody-red). Confocal images show the presence of GFP-positive cells, but no detectable DCX-positive cells in Pten-deleted DG. D, E, confocal images showing presence of Tuj1-positive cells among GFP-positive cells $(\boldsymbol{D})$ and Pten-negative cells $(\boldsymbol{E})$. Inset in mutant panel is a higher magnification of the boxed area (D). $\boldsymbol{F}$, Presence of Calbindin-positive cells among Pten-negative cells. $\boldsymbol{G}$, Experimental scheme for assessing the long-term survival and differentiation in Pten-deleted NSCS. $\boldsymbol{H}$, Confocal images showing Pten-deleted DG stained for BrdU (green) and NeuN (red) (top), and BrdU and $S 100 \beta$ (bottom). Scale bars: $A, C, D, E, I, 50 \mu \mathrm{m} ; \boldsymbol{F}, 200 \mu \mathrm{m}$.

cells \pm SEM; $n=4$; Student's $t$ test; $p<0.05$ ) and $42 \%$ more $\mathrm{GFAP}^{+}$cells in Pten $^{-/-}$cells compared with Pten ${ }^{\text {loxp/loxp }}$ control cells (33.6 \pm 3.4 in controls vs $48 \pm 2$ in mutants; percentage of $\mathrm{GFAP}^{+}$cells among Topro3 ${ }^{+}$cells \pm SEM; $n=3$; Student's $t$ test; $p<0.05)$. Therefore, in culture, Pten deletion accelerates differentiation.

\section{In vivo Pten deletion in adult neural stem cells}

To assess the role of Pten in controlling adult hippocampal NSC neurogenesis in vivo, Nestin-creER ${ }^{T 2} ;$ Pten $^{\text {loxp/loxp }}$ mice and littermate Pten ${ }^{\text {loxp } / l o x p}$ mice were treated with tamoxifen at 1 month of age and examined 3 or 6 months later to measure levels of proliferation and differentiation. In agreement with our in vitro results, staining with the mitotic cell marker Ki67 showed that mutant mice have a 1.9- and 1.4-fold increase in $\mathrm{Ki}^{+}{ }^{+}$cells at 4 and 7 months, respectively (Fig. 5A,B). To confirm that $\mathrm{Ki}^{+}{ }^{+}$cells represent proliferating stem/progenitor cells, we injected 7-month-old mice with BrdU, an S-phase marker, $2 \mathrm{~h}$ before perfusion and double-stained brain sections from mutant and control mice with anti-BrdU and anti-Sox 2 antibodies. Sox 2 is a progenitor cell marker. We observed no difference between control and mutant mice in percentage of $\mathrm{BrdU}^{+}$cells that were also Sox ${ }^{+}$, suggesting that the majority of proliferating cells in both groups represent stem/progenitor cells (73.2 \pm 11.9 in controls vs $71.2 \pm$ 13.8 in mutants; $n=5$ for control; $n=4$ for mutant; Student's $t$ test; $p=0.3)$.

To assess the in vivo role of Pten in hippocampal NSC differentiation, we analyzed mice deleted for Pten in NSCs at 1 month of age using neurogenic markers at subsequent times. We used anti-DCX and anti-NeuN antibodies to label immature and ma- 
A

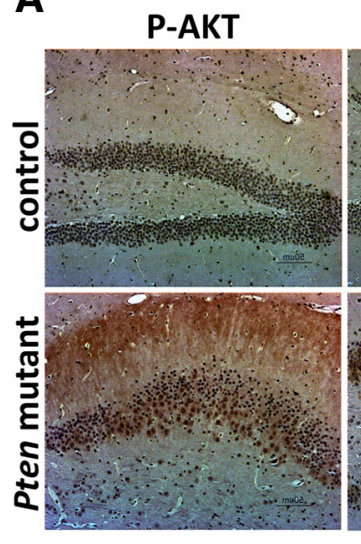

P-S6

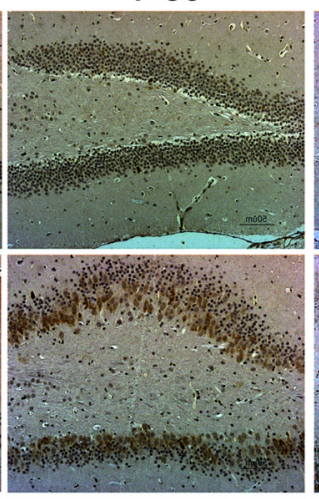

P-GSK3ß

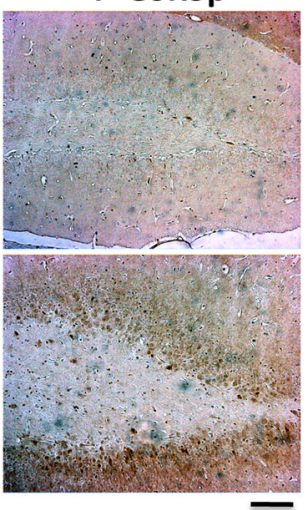

B

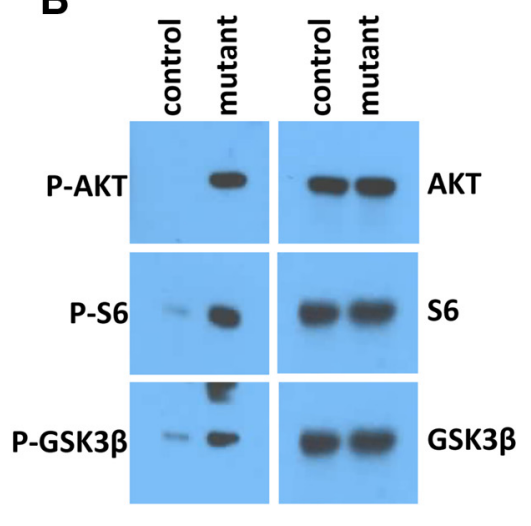

Figure 7. Loss of PTEN results in activation of downstream signaling pathways. $A$, Brain sections from 7-month-old mice were immunostained for phospho-AKT (P-AKT), phospho-S6 (P-S6), and phospho-GSK3 $\beta$ (P-GSK3 $\beta$ ); brown signals. The increase in P-AKT and P-GSK3 $\beta$ was evident in both SGZ and ML. The increase in P-S6 was only observed in SGZ layer. Scale bar, $200 \mu$ m. $\boldsymbol{B}$, Representative Western blotting images showing the increase of P-AKT, P-S6, and P-GSK3 $\beta$ in lysates from isolated DG of mutant mice.

ture neurons, respectively. At 2 months of age, both control and mutant SGZ had a similar number of $\mathrm{DCX}^{+}$cells; however, more dendritic arborization was observed in $\mathrm{DCX}^{+}$cells in the mutants (Fig. 6A). By 4 months of age, the Pten mutant mice displayed a 1.3-fold increase in $\mathrm{DCX}^{+}$cells compared with controls, but the number of $\mathrm{DCX}^{+}$cells was sharply decreased by 7 months of age in Pten KO mice, and in the majority of cases, few or no $\mathrm{DCX}^{+}$cells were detectable (Fig. 6A,B).

To better follow the fate of Pten-deleted NSCs in SGZ at 7 months, we crossed Nestin-creER ${ }^{T 2} ;$ Pten $^{\text {loxp/loxp }}$ mice to Rosa-Stop-

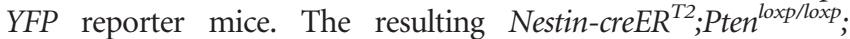
Rosa-stop-YFP mice were induced with tamoxifen at 1 month of age and examined at 7 months. Double staining with DCX and GFP antibodies labeled SGZ cells that were born after induction and confirmed the loss of DCX ${ }^{+}$cells in Pten-deleted SGZ cells. In contrast, Pten ${ }^{\text {loxp } / l o x p} ;$ Rosa-stop-YFP control mice had visible $\mathrm{DCX}^{+}$cells in the SGZ at this age (Fig. $6 C$ ). To examine whether the reduction in $\mathrm{DCX}^{+}$cells in the SGZ of Pten mutants was an indication of fewer neurons in mutant mice, we stained brain sections from Pten mutants and controls with markers of immature and mature neurons. We observed that some of the $\mathrm{YFP}^{+}$ cells were also Tuj $1^{+}$, suggesting that some of the mutant granule cells had become immature neurons (Fig. 6D). Similarly, staining with PTEN and Tuj1 antibodies confirmed that some of the Ptendeleted granule cells were Tuj ${ }^{+}$(Fig. 6E). Furthermore, doublestaining with PTEN and Calbindin antibodies showed that some of the Pten-deleted cells had become mature neurons (Fig. 6F). Therefore, while SGZ of 7-month-old control mice contained newly generated neurons, most of the Pten-null cells had progressed to resemble mature neurons. These results are consistent with our in vitro results and demonstrate accelerated differentiation of Pten mutant SGZ progenitors in vivo.

To assess the long-term survival and differentiation of Ptendeleted NSCs, we gave mutant and control mice five doses of BrdU by injection 5-6 months after tamoxifen induction and analyzed them 4 weeks after the last injection (Fig. 6G). We detected a 4.5 -fold increase in the number of $\mathrm{BrdU}^{+}$cells in Pten mutants compared with controls, confirming the continuous increase of proliferation in Pten-deleted DG (Fig. $6 H ; 6 \pm 1.7$ in controls vs $27.3 \pm 3.4$ in mutants; number of $\mathrm{BrdU}^{+}$cells \pm SEM; $n=5$ for control and $n=6$ for mutant; Student's $t$ test; $p<$ $0.01)$. Next, we performed fluorescence immunostaining using antibodies for mature neurons (NeuN) or mature astrocytes
(S100B) to determine the fate of the BrdU-labeled cells 4 weeks after they were born. We found that the majority of $\mathrm{BrdU}^{+}$cells in mutant DG colocalized with $\mathrm{S}_{100 \mathrm{~B}^{+}}(30 \pm 7.8$ in controls vs $87.2 \pm 6$; percentage of $\mathrm{S} 100 \mathrm{~B}^{+}$cells among BrdU ${ }^{+}$cells $\pm \mathrm{SEM}$; $n=10$ for controls and $n=8$ for mutants; Student's $t$ test; $p<$ $0.001)$ rather than $\mathrm{NeuN}^{+}$cells $(59.8 \pm 12.45$ in controls vs $12 \pm$ 2.5 in mutants; percentage of $\mathrm{NeuN}^{+}$cells among BrdU ${ }^{+}$cells; $n=7$; Student's $t$ test; $p<0.01)$. Together, these results indicate that Pten deletion in the NSCs of 1-month-old mice results in a surge in neurogenesis that results in relative depletion of the neuronal stem cell pool by 7 months of age.

\section{Pten deletion affects downstream AKT/mTOR/GSK3 $\beta$ signaling pathways}

Previously, it was shown that Pten-deleted neurons have increased levels of P-AKT, P-S6, and P-GSK3 $\beta$, markers for activation of AKT and mTOR, and inactivation of GSK3 $\beta$ signaling pathways, respectively (Kwon et al., 2003, 2006). Furthermore, rapamycin, a specific inhibitor of mammalian target of rapamycin complex 1 (mTORC1), ameliorated PTEN-associated abnormal neuronal phenotypes (Zhou et al., 2009). Using immunohistochemistry, we observed that deletion of Pten in young adult SGZ NSCs caused an increased level of P-AKT in both SGZ and ML of dentate gyrus (Fig. 7A), suggesting that AKT signaling was increased in both soma and dendrites of granule neurons. GSK3 has been shown to be a key regulator in multiple neurodevelopmental processes, such as neurogenesis and axonal growth and polarization (Hur and Zhou, 2010). AKT is known to phosphorylate GSK3 $\beta$ at Ser9 leading to inactivation of GSK3 $\beta$ (Cross et al., 1995). Our mutant mice also showed elevated levels of P-GSK3 $\beta$ compared with controls (Fig. 7A). In contrast, increased P-S6 level is only seen in the soma of granule neurons in the SGZ layer (Fig. 7A). Western blot analysis on lysates from isolated dentate gyrus confirmed these results and demonstrated that only phosphorylated AKT, S6 and GSK3B protein levels were elevated, while the total level of these proteins remained the same (Fig. 7B). Therefore, following Pten deletion in young adult NSCs, important downstream signaling pathways are affected.

\section{Behavioral defects}

Germline mutations in Pten have been reported in ASD families with macrocephaly (Butler et al., 2005; Varga et al., 2009). Previously, we showed that Nse-cre;Pten ${ }^{\text {loxp/loxp }}$ mutant mice in which 


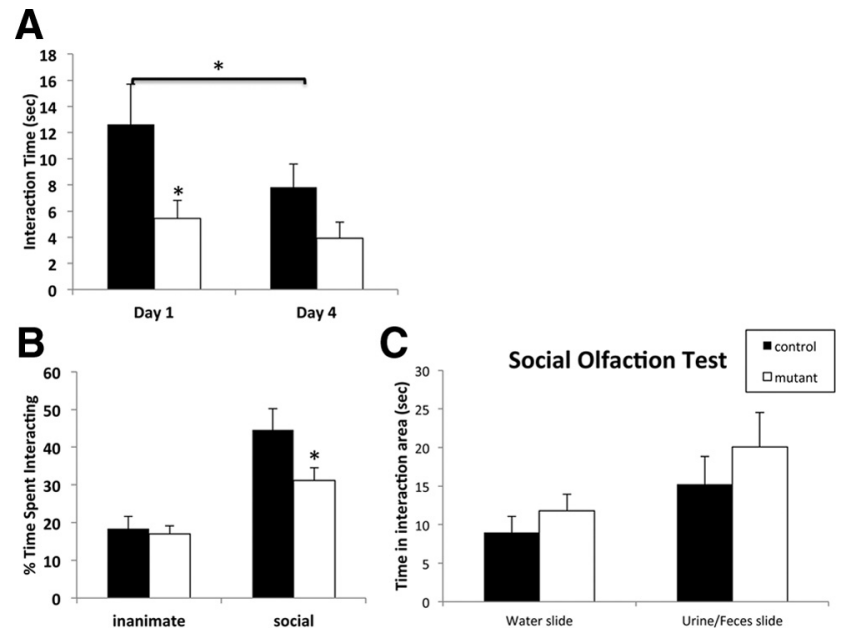

Figure 8. Deletion of Pten from adult NSCS results in deficits in social interactions. $\boldsymbol{A}$, At day 1 , mutant mice spent less time interacting with a conspecific juvenile compared with control mice ( $n=11$ for control; $n=14$ for mutant). Three days later, control mice showed less interaction with the same juvenile, but mutant mice did not decrease their interactions ( $p=$ 0.4 ; Student's $t$ test). $\boldsymbol{B}$, In a social interaction test, mutant mice spent less time interacting with social target compared with control. Interaction time with an inanimate object was similar in both groups ( $n=14$ for control; $n=15$ for mutant; ${ }^{*} p<0.05$; Student's $t$ test). $C$, In a social olfaction test, mutant mice were able to distinguish between water and urine/feces slides similar to control mice ( $n=8$ for control; $n=10$ for mutant; $p=0.8$ for water slides and $p=$ 0.3 for urine/feces slides; Student's $t$ test).
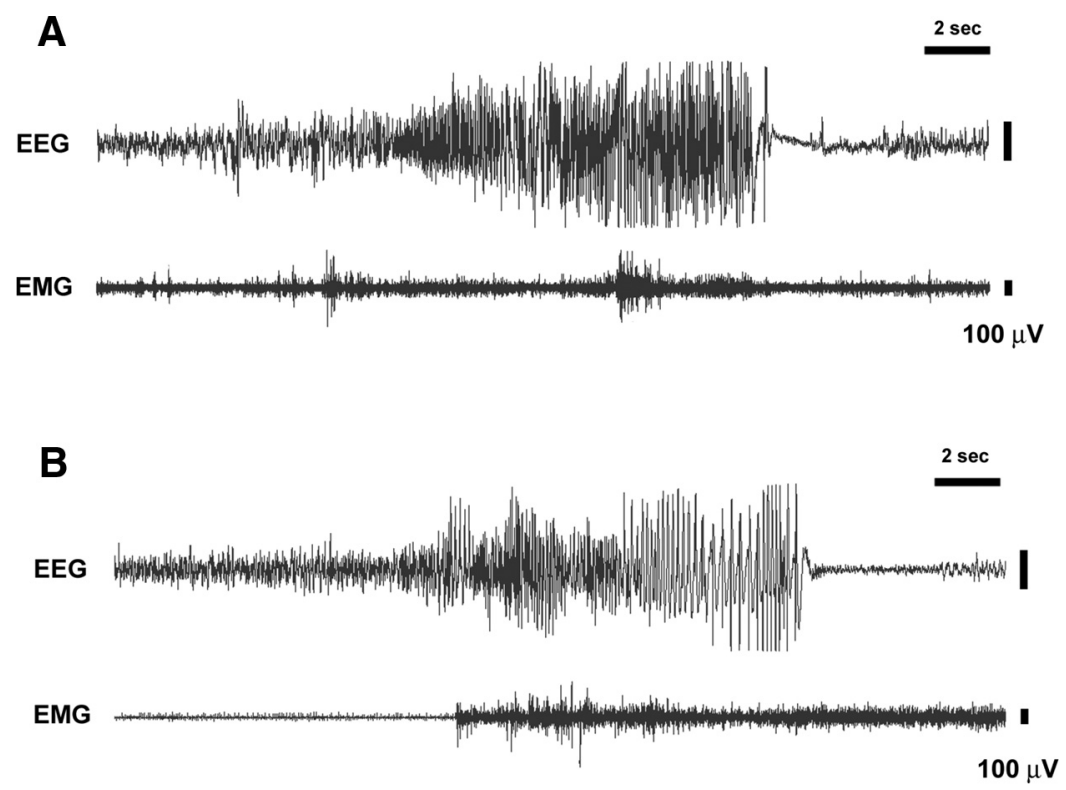

Figure 9. Deletion of Pten results in intermittent seizures. EEG/EMG recordings from 2 mutant mice showing the duration and form of typical ictal events. $A$, The seizure begins during normal wakefulness as evidenced by the low-amplitude, mixed-frequency EEG combined with elevated EMG activity. Note that the amplitude of the seizure gradually increases while the dominant frequency remains constant at 8-10 Hz. After $11.4 \mathrm{~s}$, the ictal event terminates with a single spike/wave discharge followed by post-ictal EEG slowing and reduced amplitude, which continues for $\sim 200 \mathrm{~s}$ (data not shown) before the EEG signal normalizes. $\boldsymbol{B}$, The seizure begins during REM sleep as evidenced by the continuing low-amplitude, mixed-frequency EEG combined with EMG atonia. Note that the heart rate signal can be observed on the EMG lead during muscle atonia. In this example, the seizure amplitude increases while the dominant frequency decreases from 8-10 Hz to 5- $6 \mathrm{~Hz}$. After $11.2 \mathrm{~s}$, the ictal event is terminated by a single spike/wave discharge followed by post-ictal slowing that continues for $\sim 180$ s (data not shown). Scale bars for time and amplitude as indicated.

Pten was deleted in a subset of postmitotic neurons in the cortex and hippocampus have deficits in social activity, learning, reaction to sensory stimuli, anxiety-like behaviors, and sporadic seizures, which are all features associated with human ASDs (Kwon et al., 2006; Ogawa et al., 2007). Therefore, we were interested to see whether deleting Pten specifically in SGZ and SVZ adult NSCs, without cortical or CA3 involvement, would result in similar defects. The Nestin-creER ${ }^{T 2}$ Pten ${ }^{\text {loxp/loxp }}$ mice induced at 4 weeks of age appeared normal until $\sim 4-5$ months of age, when they began displaying hyperactive behaviors and resistance to handling. In standard juvenile social interaction tests, mutant mice showed significantly less interaction with juveniles compared with controls at day 1 (Fig. $8 \mathrm{~A}$ ). When reexposed to the same juvenile $3 \mathrm{~d}$ later, control mice had decreased interactions, gesting recognition of the familiar juveniles. Mutant mice, however, did not show less interaction, suggesting lack of recognition of the same juvenile.

In a second social interaction test, we measured the amount of me mutant and control mice spent interacting with an inaniobject compared with a social target. While both groups object, mutant mice spent significantly less time interacting with the social target (Fig. $8 \mathrm{~B}$ ). Overall, motor activities were the same between both groups, suggesting that the difference between muactivity (data not shown).

Tamoxifen induction of Nestin-creER ${ }^{T 2} ;$ Pten $^{\text {loxp/loxp }}$ mice induces PTEN loss in both SGZ and SVZ neurons. The SVZ primarily generates new neurons in the olfactory bulb and therefore deficits in olfaction could contribute to behavioral changes. We performed social olfactory tests on the mutant mice and did not detect any differences in olfaction between mutant and control mice (Fig. 8C). This finding is in agreement with recent results from Wei et al. who found that blocking adult neurogenesis did not cause gross olfactory deficits (Wei et al., 2011). These results suggest that Nestin-creER ${ }^{T 2} ;$ Pten $^{\text {loxp/loxp }}$ mice, while still capable of social recognition, have indications of impaired ability in social interaction.

\section{Pten deletion causes infrequent generalized seizures}

We also monitored 10 adult Nestin-cre$E R^{T 2}$;Pten ${ }^{\text {loxp/loxp }}$ male mice for seizures using chronically implanted EEG/EMG electrodes. Six of these mice demonstrated no evidence of seizures during prolonged recording periods. Seizures were also rare events in the remaining 4 mice and only 14 seizures were observed from these records, indicating an inter-ictal interval of $\sim 74 \mathrm{~h}$. Each seizure event took the form of a generalized discharge with a high-amplitude, high-frequency burst of activity of varying frequency, followed by a post-ictal period of low-frequency, low voltage activity. The ictal event had a duration of $\sim 10 \mathrm{~s}$ (range 9.5-11.6 s) and the post-ictal slowing of the EEG signal occurred during the subsequent period of between 50 and $200 \mathrm{~s}$. Motor activity was unremarkable during the seizures with normal muscle tonus evident throughout the ictal and post-ictal periods. However, seizures were very similar in duration and formed across the mice and, interestingly, they could be initiated 
during normal wakefulness and rapid eye movement (REM) sleep. Figure 9 shows ictal events beginning in both wakefulness (Fig. 9A) and REM sleep (Fig. 9B); these examples were recorded from different mice and show the similarity of the duration and form of the seizure events across animals. In addition to these seizures, the EEG recordings of these mice occasionally showed single spikes of relatively high amplitude but these were also rare events and were not associated with subsequent slowing of the EEG or changes to EMG activity. They have therefore not been included in this analysis.

\section{Discussion}

In this study we demonstrate that Pten-deleted adult NSCs are able to develop into mature granule neurons and integrate into the existing granule layer. However, Pten-deleted granule neurons displayed hypertrophy of soma, enlarged mossy fiber axons, elongated dendrites with increased dendritic arborization, and abnormal polarity. As a result of this granule neuron hypertrophy, the dentate gyrus was enlarged and disorganized. These phenotypes closely resemble the neuronal abnormalities observed in Nse-cre;Pten loxp/loxp mutant mice in which Pten was deleted in differentiated neurons (Kwon et al., 2006). The PI3K/AKT/ $\mathrm{mTOR} / \mathrm{GSK} 3 \beta$ pathway has been suggested to be pivotal in controlling neuronal growth and polarity (Backman et al., 2001; Kwon et al., 2001, 2006; Jiang et al., 2005; Yoshimura et al., 2005; Hur and Zhou, 2010). In fact, rapamycin reversed neuronal hypertrophy and polarity in Nse-cre;Pten ${ }^{\text {loxp/loxp }}$ mutant mice, providing evidence that the mTORC1 pathway is critical for the phenotype of Pten-deleted neurons (Zhou et al., 2009). In this study, we observed that upon Pten deletion in adult NSCs, molecular markers of downstream PI3K pathway activity such as P-AKT, P-S6 and P-GSK3 $\beta$ were also increased. These results further confirm the role of PI3K/AKT/mTOR/GSK3 $\beta$ in the axonal and dendritic growth and establishment of polarity in granule neurons.

PTEN/AKT/GSK3 $\beta$ signaling pathways have also been suggested to be essential for coordinating neurogenesis $(\mathrm{Qu}$ and Shi, 2009; Hur and Zhou, 2010). Here we find that loss of Pten in adult NSCs in the SGZ leads to increased proliferation and differentiation both in vitro and in vivo. Under the temporal conditions of Pten ablation in vivo used in this study, enhanced proliferation of Pten-deleted adult NSCs is followed by an apparent subsequent depletion of neuronal stem cells in hippocampus. Stem cell self-renewal is regulated by a variety of signaling pathways. The Hedgehog, Wnt, FGF, and Notch pathways are known to promote stem cell self-renewal (Taipale and Beachy, 2001; Molofsky et al., 2005), while tumor suppressors such as p53, p16 $6^{\mathrm{INK} 4 \mathrm{a}}$ and $\mathrm{p} 19^{\mathrm{ARF}}$ inhibit this process (Molofsky et al., 2005). The effect of these pathways may depend on the lineage of the stem cells or the microenvironment in which stem cells reside. For example, conditional deletion of Pten in adult NSCs in the SEZ leads to enhanced stem cell self-renewal and expansion of NSCs (Gregorian et al., 2009). However, similar to our observation, PTEN deletion or mTORC1 activation in the stem cell compartment of several tissues, including hematopoietic stem cells, causes an increase in proliferation, but subsequent depletion of the stem cells, a phenomenon known as stem cell "exhaustion" (Yilmaz et al., 2006; Zhang et al., 2006; Castilho et al., 2009; Gan and DePinho, 2009). One possible explanation for the different consequences of deleting Pten in SGZ versus SVZ might be the fact that these two regions produce different neuronal subtypes. In addition, the role of adult neurogenesis in the hip- pocampus versus $\mathrm{OB}$ is not the same. In the $\mathrm{OB}$, postnatal/ adult neurogenesis is responsible for replacing the majority of granule neurons and therefore it is critical for $\mathrm{OB}$ maintenance as well as function (Goldman, 1998). In the hippocampus, adult neurogenesis serves to add new neurons (rather than replacing them) and is responsible for DG growth (rather than DG maintenance) (Imayoshi et al., 2008; Meeks and Holy, 2008). Therefore, it might be crucial to have a more abundant pool of stem cells in OB than in hippocampus.

Our findings are in agreement with a recent in vivo clonal analysis study that showed Pten deletion in quiescent NestinGFAP-expressing radial glia-like (RGL) precursor cells in the adult SGZ results in depletion of the RGL pool by increasing astrocytic terminal differentiation within a 1 month period (Bonaguidi et al., 2011). Similarly, we observed that new BrdUlabeled cells preferentially differentiate into astrocytes rather than neurons 4 months after PTEN deletion.

Although the precise role of hippocampal adult neurogenesis is still under debate, a number of studies have pointed to its importance in the response to antidepressants, accumulation of new memories, and learning throughout life (Saxe et al., 2006; Dupret et al., 2008; Li et al., 2008; Zhang et al., 2008). Hippocampus is also one of the regions that has been implicated in autism. Recent data suggest that autism may be caused by multiple genetic risk factors that interrupt the development and function of brain circuits important for social cognition and language (Abrahams and Geschwind, 2010). Diverse anatomical and cellular abnormalities have been reported in brains from idiopathic ASD individuals. In addition to hippocampus, reports have implicated multiple structures of the brain including: cerebral cortex, cerebellum, and amygdala in forebrain (Bauman and Kemper, 2005).

In our previous study, we used Nse-Cre to delete PTEN in mature neurons of cerebral cortex as well as the dentate gyrus and CA3 region of the hippocampus (Kwon et al., 2006; Ogawa et al., 2007). The Pten-deficient mice displayed deficiencies in classic social interaction paradigms designed to test autism-like behavior in mice (Crawley, 2004). In addition, mutant mice had an exaggerated reaction to sensory stimuli, anxiety-like behaviors, seizures, and decreased learning, which are all features associated with ASDs. In the present study, PTEN was deleted only in adult NSCs of SVZ and DG. By comparing our current Nestin-cre; Pten ${ }^{\text {loxphloxp }}$ phenotype with our previous model, Nse-cre; Pten ${ }^{\text {loxploxp }}$, we sought to investigate the role of hippocampal DG in development of the traits previously observed. Interestingly, while the mutant mice showed deficiencies in social interaction tests and infrequent seizures, we did not detect significant differences in the reaction to sensory stimuli or anxiety-like behaviors. These results further narrow down the role of hippocampal DG in the development of a subset of autism features. Furthermore, our results provide some evidence of the requirement for adult stem cells in the function of hippocampus, and a potential role in the disruption of social behaviors.

\section{References}

Abrahams BS, Geschwind DH (2010) Connecting genes to brain in the autism spectrum disorders. Arch Neurol 67:395-399.

Amaral DG (1978) A Golgi study of cell types in the hilar region of the hippocampus in the rat. J Comp Neurol 182:851-914.

Babu H, Cheung G, Kettenmann H, Palmer TD, Kempermann G (2007) Enriched monolayer precursor cell cultures from micro-dissected adult mouse dentate gyrus yield functional granule cell-like neurons. PLoS One 2:e388.

Backman SA, Stambolic V, Suzuki A, Haight J, Elia A, Pretorius J, Tsao MS, 
Shannon P, Bolon B, Ivy GO, Mak TW (2001) Deletion of Pten in mouse brain causes seizures, ataxia and defects in soma size resembling Lhermitte-Duclos disease. Nat Genet 29:396-403.

Bauman ML, Kemper TL (2005) Neuroanatomic observations of the brain in autism: a review and future directions. Int J Dev Neurosci 23:183-187.

Bonaguidi MA, Wheeler MA, Shapiro JS, Stadel RP, Sun GJ, Ming GL, Song H (2011) In vivo clonal analysis reveals self-renewing and multipotent adult neural stem cell characteristics. Cell 145:1142-1155.

Butler MG, Dasouki MJ, Zhou XP, Talebizadeh Z, Brown M, Takahashi TN, Miles JH, Wang CH, Stratton R, Pilarski R, Eng C (2005) Subset of individuals with autism spectrum disorders and extreme macrocephaly associated with germline PTEN tumour suppressor gene mutations. J Med Genet 42:318-321.

Buxbaum JD, Cai G, Chaste P, Nygren G, Goldsmith J, Reichert J, Anckarsäter H, Rastam M, Smith CJ, Silverman JM, Hollander E, Leboyer M, Gillberg C, Verloes A, Betancur C (2007) Mutation screening of the PTEN gene in patients with autism spectrum disorders and macrocephaly. Am J Med Genet B Neuropsychiatr Genet 144B:484-491.

Caldwell MA, He X, Wilkie N, Pollack S, Marshall G, Wafford KA, Svendsen CN (2001) Growth factors regulate the survival and fate of cells derived from human neurospheres. Nat Biotechnol 19:475-479.

Castilho RM, Squarize CH, Chodosh LA, Williams BO, Gutkind JS (2009) mTOR mediates Wnt-induced epidermal stem cell exhaustion and aging. Cell Stem Cell 5:279-289.

Chen J, Kwon CH, Lin L, Li Y, Parada LF (2009) Inducible site-specific recombination in neural stem/progenitor cells. Genesis 47:122-131.

Clelland CD, Choi M, Romberg C, Clemenson GD Jr, Fragniere A, Tyers P, Jessberger S, Saksida LM, Barker RA, Gage FH, Bussey TJ (2009) A functional role for adult hippocampal neurogenesis in spatial pattern separation. Science 325:210-213.

Crawley JN (2004) Designing mouse behavioral tasks relevant to autisticlike behaviors. Ment Retard Dev Disabil Res Rev 10:248-258.

Cross DA, Alessi DR, Cohen P, Andjelkovich M, Hemmings BA (1995) Inhibition of glycogen synthase kinase-3 by insulin mediated by protein kinase B. Nature 378:785-789.

Dupret D, Revest JM, Koehl M, Ichas F, De Giorgi F, Costet P, Abrous DN, Piazza PV (2008) Spatial relational memory requires hippocampal adult neurogenesis. PLoS One 3:e1959.

Endersby R, Baker SJ (2008) PTEN signaling in brain: neuropathology and tumorigenesis. Oncogene 27:5416-5430.

Eng C (2003) PTEN: one gene, many syndromes. Hum Mutat 22:183-198.

Fraser MM, Zhu X, Kwon CH, Uhlmann EJ, Gutmann DH, Baker SJ (2004) Pten loss causes hypertrophy and increased proliferation of astrocytes in vivo. Cancer Res 64:7773-7779.

Gan B, DePinho RA (2009) mTORC1 signaling governs hematopoietic stem cell quiescence. Cell Cycle 8:1003-1006.

Goffin A, Hoefsloot LH, Bosgoed E, Swillen A, Fryns JP (2001) PTEN mutation in a family with Cowden syndrome and autism. Am J Med Genet 105:521-524.

Goldman SA (1998) Adult neurogenesis: from canaries to the clinic. J Neurobiol 36:267-286.

Gregorian C, Nakashima J, Le Belle J, Ohab J, Kim R, Liu A, Smith KB, Groszer M, Garcia AD, Sofroniew MV, Carmichael ST, Kornblum HI, Liu X, Wu H (2009) Pten deletion in adult neural stem/progenitor cells enhances constitutive neurogenesis. J Neurosci 29:1874-1886.

Groszer M, Erickson R, Scripture-Adams DD, Lesche R, Trumpp A, Zack JA, Kornblum HI, Liu X, Wu H (2001) Negative regulation of neural stem/ progenitor cell proliferation by the Pten tumor suppressor gene in vivo. Science 294:2186-2189.

Groszer M, Erickson R, Scripture-Adams DD, Dougherty JD, Le Belle J, Zack JA, Geschwind DH, Liu X, Kornblum HI, Wu H (2006) PTEN negatively regulates neural stem cell self-renewal by modulating G0-G1 cell cycle entry. Proc Natl Acad Sci U S A 103:111-116.

Hur EM, Zhou FQ (2010) GSK3 signalling in neural development. Nat Rev Neurosci 11:539-551.

Imayoshi I, Sakamoto M, Ohtsuka T, Takao K, Miyakawa T, Yamaguchi M, Mori K, Ikeda T, Itohara S, Kageyama R (2008) Roles of continuous neurogenesis in the structural and functional integrity of the adult forebrain. Nat Neurosci 11:1153-1161.

Jessberger S, Clark RE, Broadbent NJ, Clemenson GD Jr, Consiglio A, Lie DC, Squire LR, Gage FH (2009) Dentate gyrus-specific knockdown of adult neurogenesis impairs spatial and object recognition memory in adult rats. Learn Mem 16:147-154.

Jiang H, Guo W, Liang X, Rao Y (2005) Both the establishment and the maintenance of neuronal polarity require active mechanisms: critical roles of GSK-3beta and its upstream regulators. Cell 120:123-135.

Kwon CH, Zhu X, Zhang J, Knoop LL, Tharp R, Smeyne RJ, Eberhart CG, Burger PC, Baker SJ (2001) Pten regulates neuronal soma size: a mouse model of Lhermitte-Duclos disease. Nat Genet 29:404-411.

Kwon CH, Zhu X, Zhang J, Baker SJ (2003) mTor is required for hypertrophy of Pten-deficient neuronal soma in vivo. Proc Natl Acad Sci U S A 100:12923-12928.

Kwon CH, Luikart BW, Powell CM, Zhou J, Matheny SA, Zhang W, Li Y, Baker SJ, Parada LF (2006) Pten regulates neuronal arborization and social interaction in mice. Neuron 50:377-388.

Li J, Yen C, Liaw D, Podsypanina K, Bose S, Wang SI, Puc J, Miliaresis C, Rodgers L, McCombie R, Bigner SH, Giovanella BC, Ittmann M, Tycko B, Hibshoosh H, Wigler MH, Parsons R (1997) PTEN, a putative protein tyrosine phosphatase gene mutated in human brain, breast, and prostate cancer. Science 275:1943-1947.

Li Y, Luikart BW, Birnbaum S, Chen J, Kwon CH, Kernie SG, Bassel-Duby R, Parada LF (2008) TrkB regulates hippocampal neurogenesis and governs sensitivity to antidepressive treatment. Neuron 59:399-412.

Maehama T, Dixon JE (1998) The tumor suppressor, PTEN/MMAC1, dephosphorylates the lipid second messenger, phosphatidylinositol 3,4,5trisphosphate. J Biol Chem 273:13375-13378.

Marino S, Krimpenfort P, Leung C, van der Korput HA, Trapman J, Camenisch I, Berns A, Brandner S (2002) PTEN is essential for cell migration but not for fate determination and tumourigenesis in the cerebellum. Development 129:3513-3522.

Markus A, Zhong J, Snider WD (2002) Raf and akt mediate distinct aspects of sensory axon growth. Neuron 35:65-76.

Meeks JP, Holy TE (2008) Pavlov's moth: olfactory learning and spike timing-dependent plasticity. Nat Neurosci 11:1126-1127.

Molofsky AV, He S, Bydon M, Morrison SJ, Pardal R (2005) Bmi-1 promotes neural stem cell self-renewal and neural development but not mouse growth and survival by repressing the p16Ink4a and p19Arf senescence pathways. Genes Dev 19:1432-1437.

Ogawa S, Kwon CH, Zhou J, Koovakkattu D, Parada LF, Sinton CM (2007) A seizure-prone phenotype is associated with altered free-running rhythm in Pten mutant mice. Brain Res 1168:112-123.

Qu Q, Shi Y (2009) Neural stem cells in the developing and adult brains. J Cell Physiol 221:5-9.

Saxe MD, Battaglia F, Wang JW, Malleret G, David DJ, Monckton JE, Garcia AD, Sofroniew MV, Kandel ER, Santarelli L, Hen R, Drew MR (2006) Ablation of hippocampal neurogenesis impairs contextual fear conditioning and synaptic plasticity in the dentate gyrus. Proc Natl Acad Sci U S A 103:17501-17506.

Silverman JL, Yang M, Lord C, Crawley JN (2010) Behavioural phenotyping assays for mouse models of autism. Nat Rev Neurosci 11:490-502.

Sinton CM, Kovakkattu D, Friese RS (2009) Validation of a novel method to interrupt sleep in the mouse. J Neurosci Methods 184:71-78.

Soriano P (1999) Generalized lacZ expression with the ROSA26 Cre reporter strain. Nat Genet 21:70-71.

Suzuki A, de la Pompa JL, Stambolic V, Elia AJ, Sasaki T, del Barco Barrantes I, Ho A, Wakeham A, Itie A, Khoo W, Fukumoto M, Mak TW (1998) High cancer susceptibility and embryonic lethality associated with mutation of the PTEN tumor suppressor gene in mice. Curr Biol 8:1169-1178

Taipale J, Beachy PA (2001) The Hedgehog and Wnt signalling pathways in cancer. Nature 411:349-354.

Tee AR, Manning BD, Roux PP, Cantley LC, Blenis J (2003) Tuberous sclerosis complex gene products, Tuberin and Hamartin, control mTOR signaling by acting as a GTPase-activating protein complex toward Rheb. Curr Biol 13:1259-1268.

Varga EA, Pastore M, Prior T, Herman GE, McBride KL (2009) The prevalence of PTEN mutations in a clinical pediatric cohort with autism spectrum disorders, developmental delay, and macrocephaly. Genet Med 11:111-117.

Waite KA, Eng C (2003) BMP2 exposure results in decreased PTEN protein degradation and increased PTEN levels. Hum Mol Genet 12:679-684.

Wei L, Meaney MJ, Duman RS, Kaffman A (2011) Affiliative behavior 
requires juvenile, but not adult neurogenesis. J Neurosci 31:14335-14345.

Wiznitzer M (2004) Autism and tuberous sclerosis. J Child Neurol 19:675-679.

Yilmaz OH, Valdez R, Theisen BK, Guo W, Ferguson DO, Wu H, Morrison SJ (2006) Pten dependence distinguishes haematopoietic stem cells from leukaemia-initiating cells. Nature 441:475-482.

Yoshimura T, Kawano Y, Arimura N, Kawabata S, Kikuchi A, Kaibuchi K (2005) GSK-3beta regulates phosphorylation of CRMP-2 and neuronal polarity. Cell 120:137-149.

Yue Q, Groszer M, Gil JS, Berk AJ, Messing A, Wu H, Liu X (2005) PTEN deletion in Bergmann glia leads to premature differentiation and affects laminar organization. Development 132:3281-3291.

Zhang CL, Zou Y, He W, Gage FH, Evans RM (2008) A role for adult TLX-positive neural stem cells in learning and behaviour. Nature 451:1004-1007.
Zhang J, Grindley JC, Yin T, Jayasinghe S, He XC, Ross JT, Haug JS, Rupp D, Porter-Westpfahl KS, Wiedemann LM, Wu H, Li L (2006) PTEN maintains haematopoietic stem cells and acts in lineage choice and leukaemia prevention. Nature 441:518-522.

Zhao C, Deng W, Gage FH (2008) Mechanisms and functional implications of adult neurogenesis. Cell 132:645-660.

Zhou J, Blundell J, Ogawa S, Kwon CH, Zhang W, Sinton C, Powell CM, Parada LF (2009) Pharmacological inhibition of mTORC1 suppresses anatomical, cellular, and behavioral abnormalities in neural-specific Pten knock-out mice. J Neurosci 29:1773-1783.

Zhou J, Shrikhande G, Xu J, McKay RM, Burns DK, Johnson JE, Parada LF (2011) Tsc1 mutant neural stem/progenitor cells exhibit migration deficits and give rise to subependymal lesions in the lateral ventricle. Genes Dev 25:1595-1600. 